\title{
Leadership Challenges and Developments in the Sports Business and Management Industry
}

\section{-- A Mini Review}

\author{
Chang Wang 1, a, Mingyan Gu 2, b, PuayChin Ong ${ }^{3, ~ c}$, Qiuyu Luo ${ }^{4, d}$, \\ Yuanzhe Li ${ }^{5, \mathrm{e}}$, *
}

1. Institute for Sport Business, Loughborough University, London, E20 3BS, United Kingdom

2. School of Business \& Management, University of South Wales, Wales, CF37 1DL, United Kingdom

3. Stirling Management School, Singapore Institute of Management, Singapore, 599491, Singapore

4. School of International Trade, Universidad Complutense Madrid, Madrid, 28015, Spain

5. Asia Education Institution, Singapore, 649812, Singapore

a C.Wang-20@student.lboro.ac.uk, b 936971595@qq.com, c gmay2004@yahoo.com.sg,

d agnes1123lqy@163.com, e, * yuanzhe001@e.ntu.edu.sg

\begin{abstract}
How to effectively bring leadership to bear in teamwork as a leader is something that requires constant reflection. This is also the case in the sports industry. Based on the author's understanding of leadership theory for the application of leadership, leadership is not a separate field, but requires a continuous integration of multiple disciplines. Or more precisely, leadership for sustainability - is not a separate school of leadership thought, but a particular blend of leadership characteristics applied within a definitive context. The Cambridge University Sustainability Leadership Institute offers a definition of sustainability leaders suggesting they are individuals who are compelled to make a difference by deepening their awareness of themselves in relation to the world around them. In doing so, they adopt new ways of seeing, thinking and interacting that result in innovative sustainable solutions. This would suggest that sustainability leadership is implicitly about creating change. The purpose of this study is to describe, critically analyse, two challenges faced by leaders in the sports business and management industry. The two greatest challenges for leaders in sports business and management, are that they are caught up with the risks of failure, rather than the requirements of success, Plus they are only concerned with getting rid of the things that bind them that they don't want. Instead of expanding what could be helpful for them. This study uses a case study approach to analyses and illustrate in detail the leadership challenges in the sports industry, ultimately using the sports industry as a small point to reflect in a diffuse manner that as a leader, one must be brave and positive when faced with challenges and constantly change to seize opportunities, thus demonstrating the continued significance and transformational appeal of sustainable leadership. This paper discusses in depth and ultimately concludes that for leaders facing challenges, they should not be afraid of them, but should seize them as an opportunity to improve themselves and make what may be a weak predicament into a strong strength in themselves. Turning weaknesses into strengths and developing yourself as a leader with advantages.
\end{abstract}

Keywords: Leadership; Challenges; Sport Business and Management; Development; Sustainability Leadership.

\section{Introduction}

Based on the University of Cambridge Institute for Sustainability Leadership's definition of sustainability leadership, they are people who are compelled to make changes by deepening their understanding of their relationship with the world around them. In doing so, they adopt new ways of seeing, thinking and interacting that lead to innovative and sustainable solutions. It could be argued that sustainability leadership - or more accurately, sustainability leadership - is not a separate school of leadership thought, but rather a particular combination of leadership characteristics applied in a 
well-defined context. This suggests that sustainability leadership is implicitly about creating change. Leadership for sustainability in organizations has been one of the key issues of research in the sustainability literature. Organizational and leadership approaches that support the move towards a more sustainable society, such as instruments for environmental management and social responsibility, have been widely implemented. However, there are critical gaps in understanding how companies design strategic pathways, assess alternatives and implement sustainable transitions. While there are multiple theories and approaches on how organizations can integrate sustainability into their strategies and operations, their efforts to improve sustainability performance still lack effective and consistent results. Sustainability leadership development is therefore particularly important in organisations (Rao and Thakur, 2019).

The purpose of this paper is to describe, critically analyses on two challenges faced by leaders in the sports business and management industry. The essay will be divided into four sections. The essay will start by describing the challenges faced by leaders in sports business and management as they focus on the risk of failure rather than the requirements of success when making strategic decisions. It will also critically analyse this obsession in the context of relevant literature. This obsession can be summarized as whether the risk of failure or the requirement for success makes leaders succeed. Then, it will describe the obsession of leaders in sports business and management of getting rid of what they do not want rather than expanding what they do want. In the third part, I will offer my own view on the analysis from the first two parts. 4) Finally, the author will give an overall summary and provide a future perspective on the development of leadership in the sports business and management industry.

\section{Great Challenge}

The first major challenge for managers is that they are plagued by the risk of failure when making strategic plans or decisions, rather than the requirements of success. A 2016 Anagnostopoulos and Parganas (2016) research suggests that putting together a plan is a fascinating, yet difficult, task for any professional working in a team sports organisation (Anagnostopoulos and Parganas, 2016). Freses and Keith (2015) have stated that errors are a part of life for any company. Error prevention is frequently used as a single technique when managing mistakes in enterprises (Frese and Keith, 2015). However, the study expresses the somewhat limited view that beyond the development of a plan in an organisation or company, the decision-making process as well as the completion of day-to-day projects require leaders to prevent mistakes. So many leaders focus too much on the risk of failure in their decision-making process while ignoring what is required for success.

Firstly, for leaders, focusing only on the risk of failure may not be seen as a nuisance. A study has shown that Risk may have a financial advantage in some cases, since companies take a lot of risks (Fadun, 2013). This shows that risk is inextricably linked to possibilities, and eliminating risk diminishes the wellspring of value generation (Fadun, 2013). Therefore, for leaders, focusing on the risk of failure is a way to increase the possibility of success for their plans. For example, when a leader makes a decision based on other failures, valuing those experiences and avoiding the factors that led to them, he has a greater chance of success. This can be seen as a strength of management (Bergiel and Balsmeier, 2008). Based on the above, in my opinion. focusing on the risk of failure can be seen as a strength of a positive leader.

However, there is another side to everything, and, as a leader, it is important not only to focus on the experience of failure, but also on the requirements of success. There is evidence showing that the strategy of senior and intermediate managers determining project goals by focusing on their essential success elements has been promoted (Munro and Wheeler, 1980). So, leaders, in terms of management decisions, need to understand that the requirements of success and the risk of failure go hand in hand. Literature from 2006 suggests that Success and failure are both equally significant (McCartney and Campbell, 2006). There is more than one good mix of leadership development abilities that promote long-term profitability, and growth should be a constant effort regardless of administrative level (McCartney and Campbell, 2006). For example, leaders can make the 
requirement for success a goal in their decision-making process while constantly holding themselves to a high standard of rigour, applying emotional intelligence leadership (Haber-Curran and GuramatunhuCooper, 2019). When applying this in the workplace, it is important to constantly use self-awareness to know oneself, to hold oneself to high standards with self-discipline, and to maintain a positive attitude and motivation to strive to achieve success. At the same time, managers can use the experiences of failure as a caveat in their decision-making process. Avoiding the recurrence of these failures is a way to achieve success.

There may be many leaders who start out only focusing on the requirements of success while not having the obsession of focusing only on the risk of failure (Yang et al., 2019). Even though there are two primary components at work, research has already shown that realistic independent appraisal is a crucial aspect in the efficacy of psychological interaction in lowering congruence (Allen and Levine, 1971). Eventually, these leaders start focusing only on the risk of failure, which might be interpreted as adaptive leadership (Campbell, 2014), constantly adapting to situations in management work and adjusting one's mindset. So, will the experience of failure make a leader successful, or will the demands of success help a leader succeed? Thus, for a leader to learn to regulate the risk mindset of focusing on failure and to balance the risk of failure with the demands of success.

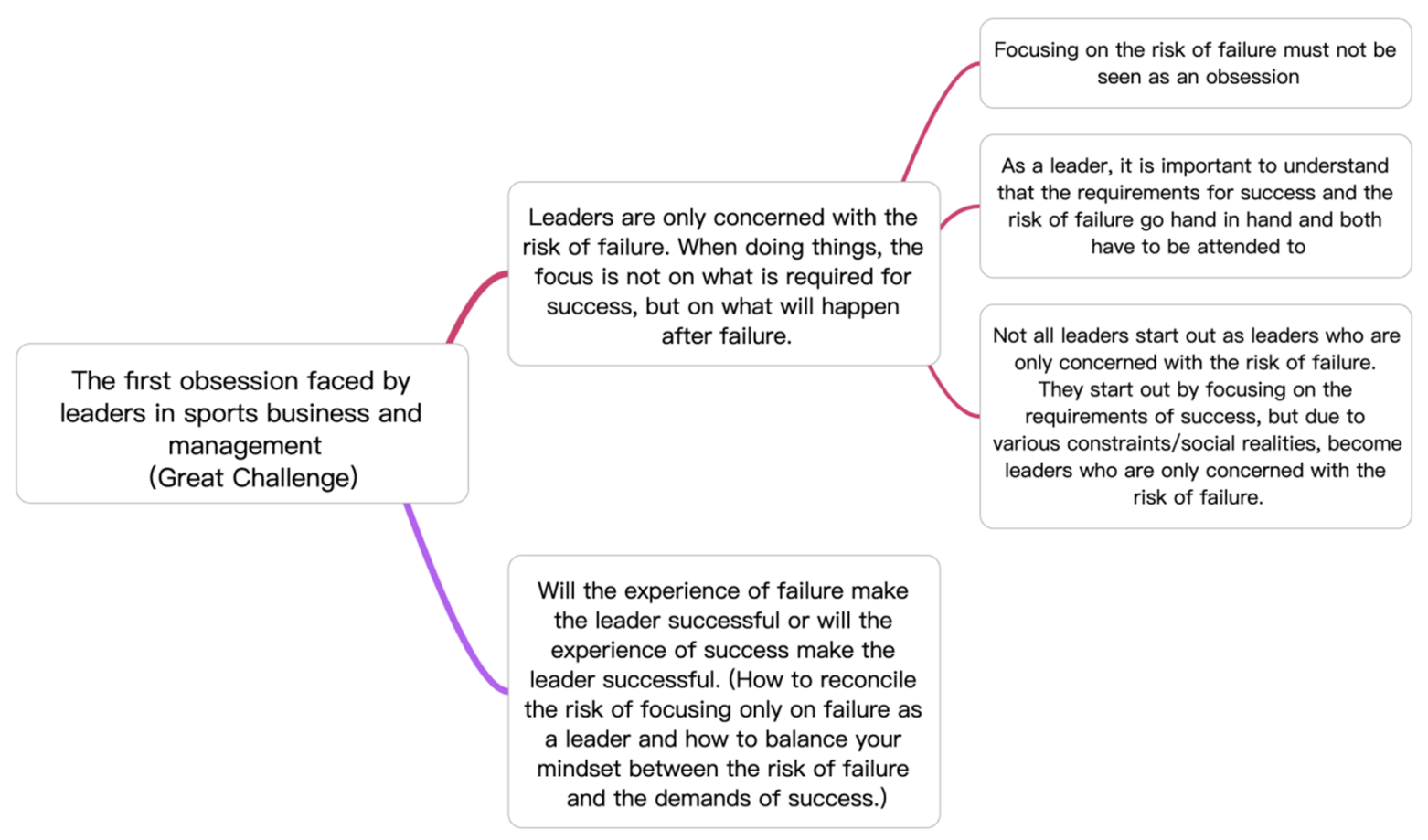

Figure 1. The number one challenge for sustainable leadership development

\section{Real Challenge}

In the management process in the sports industry, managers will have a different focus when making decisions. To improve judgment in different contexts, relevant stakeholders and stakeholders in global leadership training must focus on more points, think about more details, and relish this responsibility (Jenkins, 2012). This leads some leaders to weigh up the pros and cons in the process of making plans or strategic decisions, weighing up the process to focus on removing what is not wanted and will have a negative impact on the result, rather than actively fighting for what is wanted and makes sense. For example, in some companies involved in sports investment, staff need to gather a lot of information or primary data to produce reports to help investors make decisions. However, employing staff can be very costly for these companies. when planning to recruit while faced with 
limited financial support and an excessive number of positions, many managers reduce the number of positions while keeping salaries the same, so that one employee will do what two employees should while getting paid for 1.5 people. Few leaders choose to increase financial support to meet the salary requirements for the number of positions. The underlying reason for this challenge stems from the fact that managers want to reduce the risk of failure and aim to be positive and have a winning outcome.

According to Shechtman and Toren (2009), the control of risk can account for more than half of the decision management, and risk has a great magnitude in group activities. For some leaders, getting rid of what is not wanted is like reducing risk, because expanding what they want will require more costs and power, which will make them take the risk of failure again. So only wanting to get rid of what they do not want is the most appropriate choice for them.

But, as leaders, they should have a more strategic and holistic view of the problem and should not only think about risks. If managers only focus on getting rid of what they don't want and overlook expanding what they do want, it makes their self-aware mindset increasingly narrow (Diggins, 2021). According to the self-awareness theory, personality attention affects a wide variety of mindsets, interpretations, and behavior (Geller and Shaver, 1976). The eagerness to get out and be successful can make leaders lose their passion, positive attitude, and motivation in the face of their work. This mindset can lead to limitations in the individual development of the leader as well as the and in the development of the company as a whole. Leaders need to have a courageous and adventurous spirit, as well as servant leadership (Kantharia, 2012). The phrase "passion for work" was coined as a result of a qualitative study on businessmen's motivation, but is also described as a selfish, sexual attraction for the task (Toth et al., 2021). For example, the leaders of the Chinese sports brand Hongxing Erke help their employees in the midst of difficulties and help them to achieve self-fulfilment. In addition to this, when there are natural disasters in China, the direction of its leaders' decisions is to do their utmost to help the country and to create a positive image for society as a whole, rather than focusing on its own development and limiting itself to it. Maintain a passion for your work, get out there, expand your self-pattern, expand what you want, and ultimately achieve a win-win situation of selfrealization and achievement.

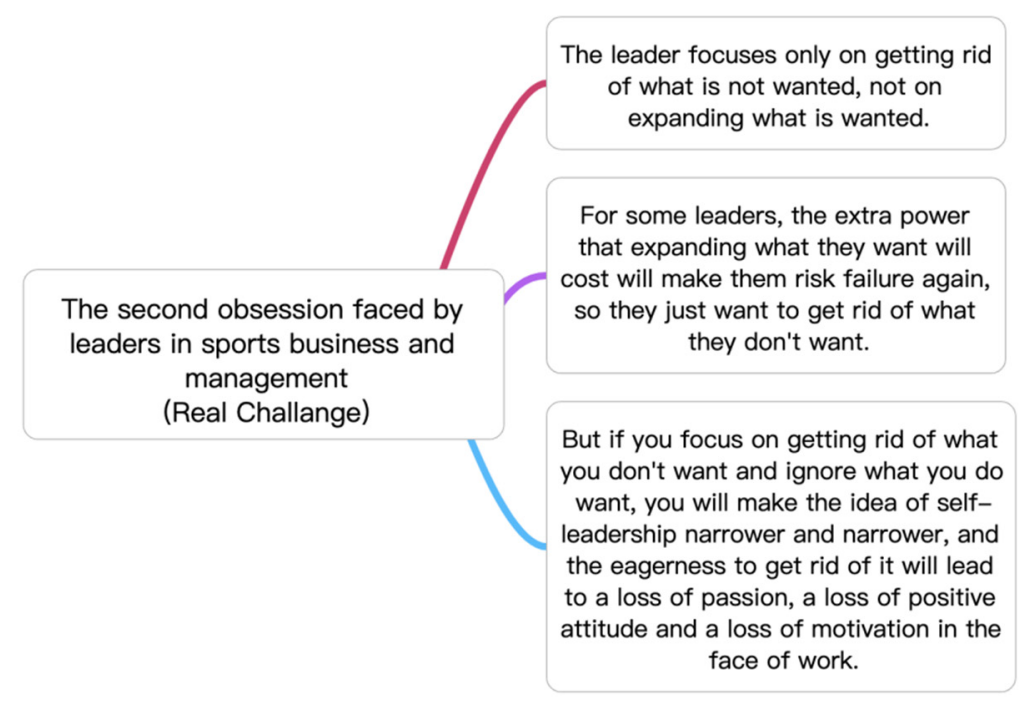

Figure 2. The number two challenge for sustainable leadership development

\section{Reflections on the Challenges}

From the two-part analysis above, it can be seen that the two questions actually end up pointing in the direction of the choice of 1 ) whether the determinant of making something happen is impacted by 
success or failure, and, more in depth, 2) what determines the success or failure of leadership decisions is based on whether the leader is getting rid of what they don't want or is expanding what they do want when making management decisions.

Based on the existing literature, when faced with the choice of expanding what the leader wants or getting rid of what the decision maker does not want, as a leader, one should do both, keeping what is right and leaving what is failing. It may be very difficult to implement, but, as a leader, it is important to uphold true leadership (Wright, 2017). The most important thing is to have a sense of the bigger picture and have the heart to help others. In addition to being responsible for yourself, you should be responsible for the development of the entire organisation. All of this is done so you can get good results in the decision-making process and help the organisation to have a better development. (For example, the leaders of Chinese sports brand Li Ning have done a great job in this regard. When it came to designing new models, from imitating the world's best to designing independent and autonomous styles, Li Ning's leadership insisted on being independent and innovative, even though this would have cost huge amounts of material and resources, in order to be more strategic, and the end result led to Li Ning becoming one of the most popular sports brands for modern young people. This has led to the brand becoming more and more successful.

Finally, leaders should not see these challenges as problems, but as an opportunity for selfimprovement. Some studies suggest that passion may allow people to understand how they feel, think, and act in order to convey meaning to our surroundings (Pollack et al., 2020). In the face of these adversities, it is important to combine the present challenges with the long-term challenges in the future. Leaders should be able to seizing these challenges and remain passionate motivated to work towards being sustainable leaders in sports business and management (Jha and Rangarajan, 2020). As a leader in particular, having a good mindset combined with a positive work ethic to maintain passion is a particularly important positive cycle.

\section{Conclusion and Prospects for the Future}

Through the above three parts of critical analysis, the following main conclusions can be drawn. For leaders in the sports business and management industry, it is important to adjust the mindset and keep passion in the face of the work. The most important thing is to approach the work with a positive mindset, to face challenges directly, to convert them into opportunities, to jump out of them, and to seize them, with the ultimate aim of being a leader who practices sustainable development.

In the future, leaders in the sports business and management industry can insist on being ambitious in their work, remain humble and positive, maintain a comprehensive sense of the bigger picture in whatever they do, be flexible in their work process, and consistently face the process with a critical attitude. Keep the good, discard the bad in time, and be a grateful leader who gets things done with a sense of self-achievement and achievement of others, self-improvement and enhancement of others.

Finally, at this stage, people who are senior leaders focus only on the results of their work and ignore the process, so this leads to a relative lack of team spirit in the whole team. This is because everyone in the work process is just like the leaders who are just chasing after the final result that the leaders want. Therefore, in the future, as a senior leaders will pay more attention to the process of work while taking into account the results, helping colleagues to grow in the process, and at the same time being a kind of self-improvement for the leaders themselves, enjoying the fun of the work process as much as possible, and finally enjoying the sense of achievement brought by positive results. Discovering the meaning of authentic leadership.

\section{Acknowledgments}

This work has been supported by Asia Education Institution (SG) since 2020, Project number: AEI210512G. 


\section{References}

[1] Allen, V. and Levine, J., 1971. Social support and conformity: The role of independent assessment of reality. Journal of Experimental Social Psychology, 7(1), pp.48-58.

[2] Anagnostopoulos, C. and Parganas, P., 2016. The Sports Strategist: Developing Leaders for a HighPerformance Industry. Sport, Business and Management: An International Journal, 6(1), pp.106-108.

[3] Bergiel, B., Bergiel, E. and Balsmeier, P., 2008. Nature of virtual teams: a summary of their advantages and disadvantages. Management Research News, 31(2), pp.99-110.

[4] Campbell, W., 2014. Adaptable Leadership: A Strengths-based Approach to Challenging Environments and Difficult Choices Introduction. AI Practitioner, 16(1), pp.4-8.

[5] Davies, B., 2008. Leadership: Theory and Practice20081Peter G. Northouse. Leadership: Theory and Practice. Thousand Oaks, CA: Sage 2007, ISBN: 978 - 1 - 4129 - 4161 - 7 4th ed. International Journal of Educational Management, 22(7), pp.710-710.

[6] Diggins, K., 2021. Self-Awareness and a Healthy Mindset. Journal of Christian Nursing, 38(2), pp.75-75.

[7] Fadun, O., 2013. Risk Management and Risk Management Failure: Lessons for Business Enterprises. International Journal of Academic Research in Business and Social Sciences, Vol. 3, No. 2 (2222-6990).

[8] Frese, M. and Keith, N., 2015. Action Errors, Error Management, and Learning in Organizations. Annual Review of Psychology, 66(1), pp.661-687.

[9] Geller, V. and Shaver, P., 1976. Cognitive consequences of self-awareness. Journal of Experimental Social Psychology, 12(1), pp.99-108.

[10] Haber-Curran, P. and GuramatunhuCooper, N., 2019. Teaching Global Mindset and Intercultural Competence Through the Framework of Emotionally Intelligent Leadership. Journal of Leadership Education, 19(2), pp.101-103.

[11] Jenkins, D., 2012. Global critical leadership: Educating global leaders with critical leadership competencies. Journal of Leadership Studies, 6(2), pp.95-101.

[12] Jha, M. and Rangarajan, K., 2020. The approach of Indian corporates towards sustainable development: An exploration using sustainable development goals-based model. Sustainable Development, 28(5), pp. 1019-1032.

[13] Kantharia, B., 2012. Servant Leadership: An Imperative Leadership Style for Leader Managers. SSRN Electronic Journal.

[14] McCartney, W. and Campbell, C., 2006. Leadership, management, and derailment. Leadership \& Organization Development Journal, 27(3), pp.190-202.

[15] Munro, M. and Wheeler, B., 1980. Planning, Critical Success Factors, and Management's Information Requirements. MIS Quarterly, 4(4), p.27.

[16] Pollack, J., Ho, V., O'Boyle, E. and Kirkman, B., 2020. Passion at work: A meta-analysis of individual work outcomes. Journal of Organizational Behavior, 41(4), pp.311-331.

[17] Rao, I. and Thakur, P., 2019. Knowledge workers, organisational ambidexterity and sustainability: a conceptual framework. International Journal of Business Excellence, 19(3), p.415.

[18] Shechtman, Z. and Toren, Z., 2009. The effect of leader behavior on processes and outcomes in group counseling. Group Dynamics: Theory, Research, and Practice, 13(3), pp.218-233.

[19] Toth, I., Heinänen, S. and Puumalainen, K., 2021. Passionate and engaged? Passion for inventing and work engagement in different knowledge work contexts. International Journal of Entrepreneurial Behavior \& Research, 27(9), pp.1-25.

[20] Wright, J., 2017. Authentic Dialogue: The Communication of Collaborative Leadership. Advances in Social Sciences Research Journal, 4(1), p.245.

[21] Yang, Y., Li, Z., Liang, L. and Zhang, X., 2019. Why and when paradoxical leader behavior impact employee creativity: Thriving at work and psychological safety. Current Psychology, 40(4), pp.19111922. 